\title{
The efficacy of primary care chaplaincy compared with antidepressants: a retrospective study comparing chaplaincy with antidepressants
}

\section{Gordon Macdonald}

GP Principal, Regent Gardens Medical Practice, Kirkintilloch, Glasgow, UK

\begin{abstract}
Aim: To determine the effectiveness of primary care chaplaincy (PCC) when used as the sole intervention, with outcomes being compared directly with those of antidepressants. This was to be carried out in a homogenous study population reflective of certain demographics in the United Kingdom. Background: Increasing numbers of patients are living with long-term conditions and 'modern maladies' and are experiencing loss of well-being and depression. There is an increasing move to utilise non-pharmacological interventions such as 'talking therapies' within this context. Chaplaincy is one such 'talking therapy' but within primary care its evidence base is sparse with only one quantitative study to date. There is therefore a need to evaluate PCC excluding those co-prescribed antidepressants, as this is not evidenced in the literature as yet. PCC also needs to be directly compared with the use of antidepressants to justify its use as a valid alternative treatment for loss of well-being and depression. Methods: This was a retrospective observational study based on routinely collected data. There were 107 patients in the PCC group and 106 in the antidepressant group. Socio-demographic data were collected. Their pre- and post-intervention (either chaplaincy or antidepressant) well-being was assessed, by the Warwick-Edinburgh Mental Well-being Scale (WEMWBS) which is a validated Likert scale. Findings: The majority of both groups were female with both groups showing marked ethnic homogeneity. PCC was associated with a significant and clinically meaningful improvement in well-being at a mean follow-up of 80 days. This treatment effect was maintained after those co-prescribed antidepressants were removed. PCC was associated with an improvement in well-being similar to that of antidepressants with no significant difference between the two groups.
\end{abstract}

Key words: antidepressants; chaplaincy; talking therapy; well-being

Received 12 September 2016; revised 8 March 2017; accepted 10 March 2017; first published online 17 April 2017

\section{Introduction}

For several years now there has been a mandate for the provision of spiritual care within the NHS (Scottish Executive Health Department HDL, 2002; Scottish Government Department of Health and Wellbeing, 2008). Such provision in primary care is

Correspondence to: Dr Gordon Macdonald, Regent Gardens Medical Practice, 18 Union St, Kirkintilloch, Glasgow G66 1DH, UK. Email: Gordon.macdonald@nhs.net somewhat behind the curve of secondary care. However, there are signs of growth with the development of the Community Chaplaincy Listening Service (Mowat et al., 2012; Bunniss, 2013) and Sandwell and West Birmingham Chaplains for Wellbeing project (Bryson et al., 2012) along with other smaller projects.

Certainly when viewed as a 'talking therapy', primary care chaplaincy (PCC) fits well into the political agenda (DOH, 2011), with a governmental desire for timeously accessible 'talking

(C) Cambridge University Press 2017 
therapies' for patients with mental health issues. Practically this can be challenging to achieve due to lack of availability. PCC typically fits well into this model due to local provision, flexible appointments and practice attached chaplains.

Spirituality within healthcare can be difficult to define. It is, however, well encapsulated by Pargament (1999) when he describes it as a search for the sacred. It can also be seen as a search for meaning in the midst of suffering but ultimately, many definitions point to the concept of transcendence (Tanyi, 2002; King and Koenig, 2009; Puchalski et al., 2009). PCC should at its best support patients who in their disease search for meaning, wholeness and indeed transcendence.

\section{Rationale for chaplaincy}

As we face the well-recognised issues of an ageing population (Christensen et al., 2009; Oliver, 2012) and the increase in long-term conditions (LTC) (Barnett et al., 2012) it will be important to utilise such PCC services. It is known that patients with LTC's experience more mental health issues (some estimate up to 30\%) (Cimpean and Drake, 2011) which affect their well-being. Patients with LTC's will do well to engage with a new definition of health (Mathers, 2014), which will require them to adapt to and self manage their multiple health issues. With such longevity and multimorbidity will come a greater awareness of physical losses, and the need for wholeness independent of their physical condition. It could be argued that, in the face of their declining physical health, patients will therefore require greater spiritual resilience (Manning, 2014) to co-exist with this new health definition. It would also seem that the concept of reducing the burden of treatment (Mair and May, 2014) in LTC's could be fulfilled by PCC as opposed to potential use of further medication such as antidepressants. Patients are often aware of their spiritual needs, value support in addressing them (Williams et al., 2011) and are receptive to spiritual care in palliative settings (Delgado-Guay, 2014). It seems reasonable to provide the same holistic care for LTC's that we provide for palliative patients. Indeed patients value spiritual needs being raised by practioners (Ehman et al., 1999; Vallurupalli et al., 2012) and are aware of their inner needs or spirituality impacting on their health.

The other cohort of patients recognised to benefit from addressing a new 'way of being'
(Mathers, 2014) and holistic health promotion are those suffering from one of the 'modern maladies' described by Hanlon et al. (2011). Hanlon describes loss of well-being (as distinct from depression), obesity, addictive behaviours and depression as the epidemics of our time. There is evidence that these conditions are possibly over medicalised and potentially medicated due to various pressures (Moscrop, 2011; Moynihan, 2011; Dowrick and Frances, 2013; Hofmann, 2016). It is also thought that such presentations reflect an underlying 'inner' or spiritual need that is not met by the prevailing philosophies of modernity such as 'materialism, individualism and consumerism' (Hanlon et al., 2011).

These very practical needs for PCC coupled with patients receptiveness creates an environment ideal for PCC.

\section{PCC intervention}

The 'type' of PCC delivered is based on the work done in the author's practice. Regent Gardens Medical Practice PCC started in 2008. It was initially based solely on the model provided by the Karis Medical Practice based in the Sandwell hub (Bryson et al., 2012). This is rooted in a 'human givens' or 'deepest human needs' (Bryson et al., 2012) approach and is informed by Maslow's hierarchy of needs (Maslow, 1943; Maslow, 1970 [1964]), addressing themes of significance and security. Over time the author's practice has developed PCC into a synthesis of the Karis model and the 'modern maladies' approach of Hanlon et al. (2011). When such modern malady presentations arise they are seen as 'cues' that may be highlighting a deeper inner need, thus prompting a referral to PCC.

It can be difficult to fully describe what happens in a PCC intervention. However, certain key features have been evidenced from the literature (McSherry et al., 2016). These resonate with the author's practice where listening with generosity of time, spiritual direction in the search for meaning and compassionate presence are key to the impact upon patient well-being.

\section{Reason for study}

There are certain rate limiting factors to such service delivery. Some of these centre around resource and practioner confidence in raising spiritual matters in the consultation (Vermandere et al., 2011). 
However, as with any new service confidence increases as evidence of effectiveness accumulates. There is to date a relatively small body of research into PCC. The study by Kevern and Hill (2015) was the first quantitative study looking at patient wellbeing before and after PCC intervention. This study showed a clinically significant improvement in patient well-being post-chaplaincy intervention. It is noteworthy that this was an ethnically diverse population with a probable richness of worldviews. A follow-up study (Kevern, 2015) identified that despite this clinical improvement in well-being, the use of resource in the form of future GP consultations and prescriptions of antidepressants did not diminish. It also seems there is a need to evaluate non-pharmacological therapies in LTC's given it is common comorbidity of mental health pathology.

In view of these findings there was felt to be an opportunity to contribute to the evaluation of PCC, further clarifying its impact on patient wellbeing. The objectives of this study were therefore threefold.

\section{Objectives}

1. Determine if PCC is associated with improvement in well-being in patients who receive this intervention alone.

2. Determine if PCC is associated with improvement in well-being relative to typical care - in this case antidepressants.

3. Determine if PCC is associated with improvement in well-being in a homogenous population.

\section{Methods}

\section{Study design}

This study was a retrospective service evaluation. It was purely observational with no allocation or randomisation occurring.

\section{Participants and setting}

This study took place entirely with patients from Regent Gardens Medical Practice. This is a suburban General Practice near Glasgow with relatively little ethnic diversity, significant economic diversity and a list size of just under 10000 . Patients aged 16 and over (Brown, 2008) attending the practice chaplain or starting antidepressants between 1 March 2015 and 1 August 2016 had their routinely collected data analysed. This time period was chosen as there was optimal continuity (prior to the chaplain's sabbatical). It also coincided with an adequate number of participants, see below for sample size calculation.

Patients were given written and verbal information at the initial contact regarding the purpose of the service evaluation. Their written consent was obtained to use this data at this first contact.

The notes of patients in the chaplaincy (C) group were reviewed once the data collection finished. This allowed identification of those co-prescribed antidepressants. These patients were removed to form the 'cleaned' chaplaincy (CC) group. There were therefore three groups: (C), (CC) a subset of (C) and the antidepressant group (AD).

\section{Intervention}

Patients were assessed by their GP and either started on an antidepressant or referred to the practice chaplain. This assessment was based solely on their usual consultation skills with patients being included in decision making. It is, however, known, from previous internal semistructured interviews, that certain factors do influence GP's referral to PCC within this practice. Speed of access into PCC is known to encourage referral. The presenting issue also has a bearing on referral. Patients with issues of bereavement, loss or psychosocial crisis are more likely to be referred. This is borne out in the results below.

The practice chaplain saw each referred patient within a week of referral. Duration of appointment was determined by the patient (up to $1 \mathrm{~h}$ ) as were the number of future appointments. Chaplaincy intervention was in line with the model described above.

\section{Assessment tool}

Warwick-Edinburgh Mental Well-being Scale (WEMWBS) is a 14-item well-being scale scored by the summation of a 1-5 Likert scale (Appendix 1). The chaplain oversaw it is administration in group (C) and the involved GP oversaw it is administration at first contact in group (AD). It was selected to evaluate the difference in pre- and postintervention well-being, as it was the rating scale used in the only other quantitative PCC study (Kevern and Hill, 2015). It is also well validated in several settings including Scotland (Braunholtz 
et al., 2007; Tennant et al., 2007; Maheswaran et al., 2012; Bartram et al., 2013). It assesses mental wellbeing as opposed to mental health and so will reduce ceiling effects that may obscure health improvement in the healthier end of a population (Brown, 2008). Although it has not been validated for use in the diagnosis of depression it was not being used for this purpose with clinician's usual judgement being relied on. It is, however, known to have a strong inverse correlation with the Centre for Epidemiologic Studies Depression (CES-D) scale for depression (Donatella, 2012). CES-D (Radloff, 1977) has frequently been used as the gold standard assessment tool in such studies. WEMWBS cut-off scores of $<40.5-41.5$ and $<44.5$ correlate highly with risk of major depression and depression, respectively. These scores equate to the CES-D cut-off scores that are most stringent for diagnosing depression and have the greatest sensitivity and specificity of $>90 \%$ (Vazquez et al., 2007).

A clinically significant improvement in wellbeing is evidenced by an increase of 7 points (Maheswaran et al., 2012).

Permission was granted for use in this project by Warwick Medical School in January 2015.

Patients were sent a post-intervention WEMWBS by means of a stamped addressed envelope for ease of return. This was sent at 6 weeks and 12 weeks with the intention of achieving at least one return. Where more than one return was received the final return was used in the data analysis. This concept of a 'final' return is utilised in the original study in PCC (Kevern and Hill, 2015).

\section{Sample size}

A formal sample size was not calculated given this was a service evaluation. However, early work done in validating the use of WEMWBS (Brown, 2008) has shown that in a list of 10000 patients a sample size of 133 patients should detect a change down to the level of 3 points, with significantly less patients required to detect a larger increment.

\section{Data management and analysis}

Data were collected and entered into respective encrypted excel sheets in line with WEMWBS guidelines (Brown, 2008). Data entry were checked by a third party who was blind to the study concept. Any missing data were handled according to the WEMWBS guidance - that is, if one item was missing from the returned questionnaire it was filled by imputation. It was given the lowest possible value. If more than one item was missing the data were discarded. Only eight questionnaires required imputation for one item of missing data and no questionnaires had more than one item missing.

GraphPad Prism 7 was used to analyse data with all patients enrolled included.

Data included pre- and post-WEMWBS scores, age, gender, employment status and ethnicity for all three groups AD, C and CC. Specific statistical test used are described in each result section.

\section{Results}

Figure 1 shows a flowchart of study participants.

The mean duration of days between first and final WEMWBS was AD 80.6 95\% confidence interval (CI) 73.3-87.8, C 80.14 95\% CI 72.9-87.3 and CC 82 95\% CI 72.3-91.7.

\section{Presenting issues}

In addition to depression or anxiety, the prevalence of issues of loss, bereavement, relationships, image or self acceptance were C $70 \%$ and AD $42 \%$.

\section{Antidepressants used}

Standard antidepressants were used as follows: sertraline 64 (42 on $50 \mathrm{mg}$, 21 on $100 \mathrm{mg}$ and 1 on $150 \mathrm{mg}$ ), citalopram 19 (3 on $10 \mathrm{mg}$ and 16 on $20 \mathrm{mg}$ ), mirtazipine 14 (11 on $15 \mathrm{mg}$ and $3 \mathrm{on} 30 \mathrm{mg}$ ), trazdone $2(50 \mathrm{mg})$, amitryptiline $3(20 \mathrm{mg})$, fluoxetine $3(20 \mathrm{mg})$ and paroxetine $1(20 \mathrm{mg})$. The average duration of antidepressant prescription was 6.3 months (median 7, mode 3 ). There was no evidence of non-prescription use of antidepressants. In total, 20 patients in the antidepressant group were advised to attend non-PCC counselling but as this was a self-referral service uptake figures were not available.

For the sake of clarity baseline characteristics were compared between the three groups but preand post-intervention WEMWBS scores were only compared between $\mathrm{AD}$ and $\mathrm{CC}$ to show the effect of PCC alone relative to antidepressants.

\section{Comparison of baseline characteristics between groups $\mathrm{AD}, \mathrm{C}$ and $\mathrm{CC}$}

The socio-demographic characteristics of each group are summarised in Table $1 . \chi^{2}$ test was used to assess data. 


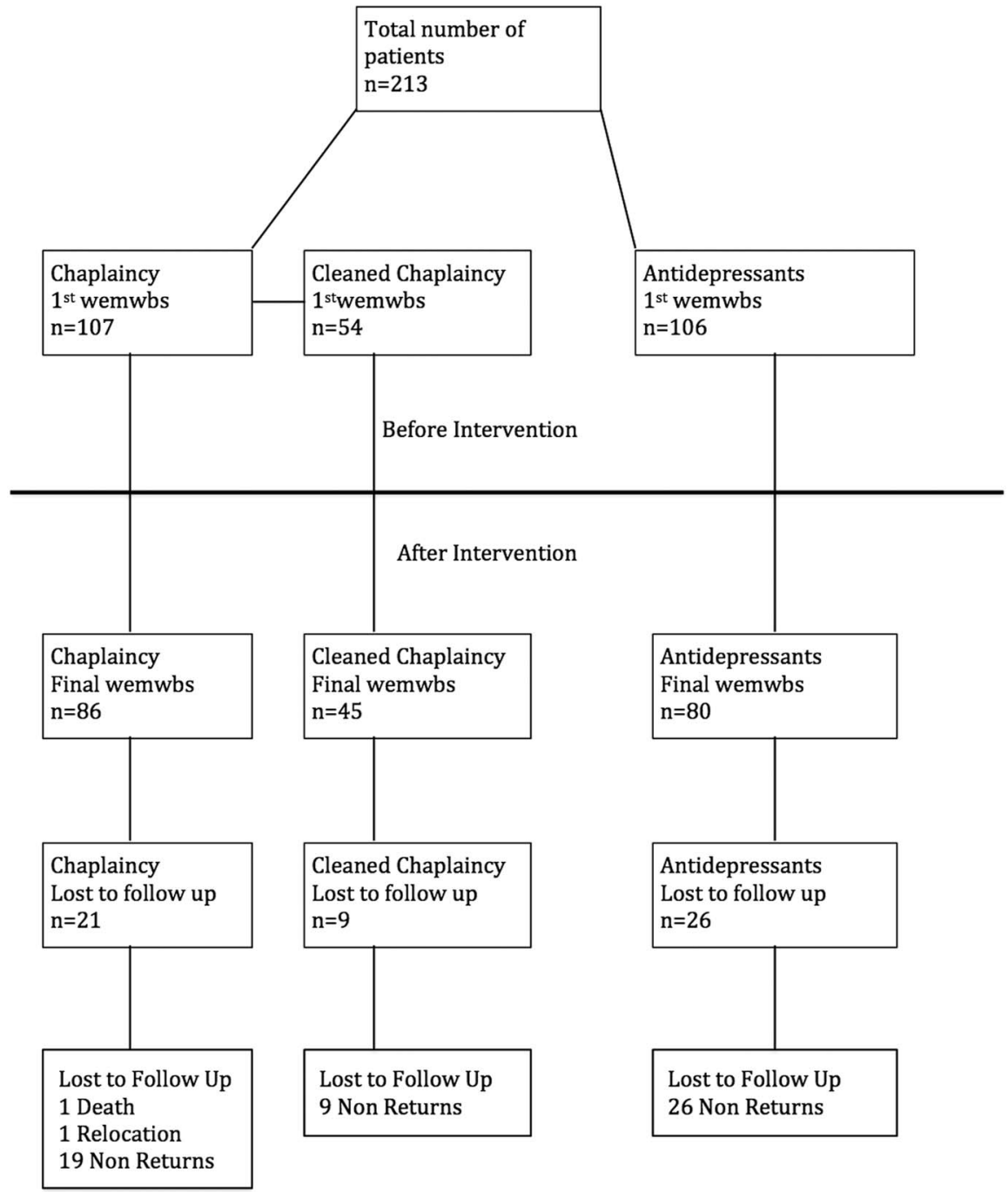

Figure 1 Flowchart of study participants.

There was no significant difference in characteristics between the groups:

a. Gender: There was a higher proportion of females than males in all three groups by a ratio of at least 3:1.

b. Employment status: The data were grouped as employed, unemployed or retired. Although the differences between groups were not significant there was a slightly higher percentage in $\mathrm{C}$ and $\mathrm{CC}$ who were retired.

Primary Health Care Research \& Development 2017; 18: 354-365 c. Ethnicity: The data were grouped as White, Black or Asian. Each group showed remarkable homogeneity, each at over $97 \%$ White. This reflects the over all practice population.

d. Age: The data were grouped in age ranges of 10 years from 16 years old. Although not reaching significance there was a slight preponderance of 25-39-year olds in the AD group and $>65$-year olds in the CC group.

e. Initial WEMWBS score: Table 2 summaries the data. Unpaired $t$ tests were used to assess data. 
Table 1 Socio-demographic status of study participants

\begin{tabular}{lclll}
\hline $\begin{array}{l}\text { Socio-demographic } \\
\text { status }\end{array}$ & $\begin{array}{l}\mathrm{AD}(n=106) \\
{[n(\%)]}\end{array}$ & $\begin{array}{l}\mathrm{C}(n=107) \\
{[n(\%)]}\end{array}$ & $\begin{array}{l}\mathrm{CC}(n=54) \\
{[n(\%)]}\end{array}$ & $\begin{array}{l}\text { Test of difference } \\
(P \text { value })^{\mathrm{a}}\end{array}$ \\
\hline $\begin{array}{l}\text { Sex } \\
\text { Male }\end{array}$ & $26(25)$ & $21(20)$ & $13(76)$ & 0.66 \\
$\quad$ Female & $80(75)$ & $86(80)$ & $41(24)$ & \\
$\begin{array}{l}\text { Ethnicity } \\
\text { White }\end{array}$ & $104(98)$ & $104(97)$ & $53(98)$ & 0.53 \\
Black & $0(0)$ & $2(2)$ & $1(2)$ & \\
Asian & $2(2)$ & $1(1)$ & $0(0)$ & \\
Age & $13(12)$ & $7(7)$ & $2(4)$ & 0.21 \\
16-24 & $35(33)$ & $26(24)$ & $14(26)$ & \\
$25-39$ & $23(22)$ & $22(21)$ & $10(19)$ & \\
$40-54$ & $17(16)$ & $23(21)$ & $10(19)$ & \\
$55-64$ & $18(17)$ & $29(28)$ & $18(32)$ & \\
$\quad>65$ & & & & \\
Employment status & $57(54)$ & $49(46)$ & $26(48)$ & 0.18 \\
$\quad$ Employed & $30(28)$ & $27(25)$ & $10(19)$ & \\
Unemployed & $19(18)$ & $31(29)$ & $18(33)$ & \\
Retired & & &
\end{tabular}

$\mathrm{AD}=$ antidepressant group; $\mathrm{C}=$ chaplaincy group; $\mathrm{CC}=$ 'cleaned' chaplaincy group.

${ }^{a} P$ value was calculated by $\chi^{2}$ test.

Table 2 Baseline WEMWBS of study participants compared between groups, expressed as a mean with standard deviation

\begin{tabular}{llll}
\hline & $\mathrm{AD}(n=106)$ & $\mathrm{C}(n=107)$ & Test of difference $^{\mathrm{a}}$ \\
\hline Baseline WEMWBS [mean (SD)] & $32.71(8.84)$ & $37.08(9.23)$ & $P$ value $=0.0005^{\mathrm{b}}$ \\
& $\mathrm{AD}(n=106)$ & $\mathrm{CC}(n=54)$ & \\
Baseline WEMWBS [mean (SD)] & $32.71(8.84)$ & $40.41(8.74)$ & $P$ value $\leqslant 0.0001^{\mathrm{c}}$ \\
\hline
\end{tabular}

WEMWBS = Warwick-Edinburgh Mental Well-being Scale; $A D$ = antidepressant group; $\mathrm{C}=$ chaplaincy group; $\mathrm{CC}=$ 'cleaned' chaplaincy group.

${ }^{\text {a }} P$ value was calculated by unpaired $t$ tests.

${ }^{\mathrm{b}} P$ value was calculated by unpaired $t$ tests comparing AD with $C$.

${ }^{\mathrm{c}} P$ value was calculated by unpaired $t$ tests comparing and AD with $C C$.

$\mathrm{AD}$ was compared with $\mathrm{C}$ and then $\mathrm{CC}$. The baselines scores were significantly different between groups, with the greatest difference being between AD and CC. However, each groups' mean baseline scores were below the 40.5-41.5 and 44.5 cut-off scores found in the Donatella (2012) paper to correlate highly with likelihood of major depression and depression, respectively. It therefore could be argued that each group is similar at baseline in terms of diagnosis but not in the extent of symptoms.

f. Followed-up (FU)/lost to follow-up (LTFU): $\chi^{2}$ test was used to test for difference in follow-up rates between the three groups as displayed in Table 3. Thus, there was no significant difference in follow-up rates between groups. Follow-up rate was noted to be high.

g. Baseline WEMWBS in FU/LTFU: Unpaired $t$ tests (and Mann-Whitney $U$ test where nonparametric) were used to compare baseline WEMWBS scores for FU and LTFU within each of the three groups. AD median (interquartile range: IQR) FU 32.5 (25-39), LTFU 35 (28.5-38), $P$ 0.27. C mean (standard deviation: SD) FU 37.86 (9.14), LTFU 34.81 (9.49), $P$ 0.18. CC median (IQR) FU 40 (35-47), LTFU 38 (33.5-45), P 0.51. 
Table 3 Loss to follow-up expressed as number and percentage

\begin{tabular}{lllll}
\hline & $\begin{array}{l}\mathrm{AD}(n=106) \\
{[n(\%)]}\end{array}$ & $\begin{array}{l}\mathrm{C}(n=107) \\
{[n(\%)]}\end{array}$ & $\begin{array}{l}\mathrm{CC} \\
(n=54)[n(\%)]\end{array}$ & $\begin{array}{l}\text { Test of } \\
\text { difference }(P \text { value })^{\mathrm{a}}\end{array}$ \\
\hline $\begin{array}{l}\text { Followed-up } \\
\text { Lost to follow-up }\end{array}$ & $\begin{array}{l}80(75) \\
26(25)\end{array}$ & $\begin{array}{l}86(80) \\
21(20)\end{array}$ & $\begin{array}{r}45(83) \\
9(17)\end{array}$ & 0.47 \\
\hline
\end{tabular}

$\mathrm{AD}=$ antidepressant group; $\mathrm{C}=$ chaplaincy group; $\mathrm{CC}=$ 'cleaned' chaplaincy group.

${ }^{a} P$ value was calculated by $\chi^{2}$ test.

Table 4 Comparison of changes in WEMWBS scores between groups expressed as mean with standard deviation

\begin{tabular}{llll}
\hline & $\mathrm{AD}(n=80)$ & $\mathrm{CC}(n=45)$ & \\
\hline Change in WEMWBS [mean (SD)] & $8.81(9.08)$ & $7.53(8.92)$ & $P$ value $=0.49$ \\
\hline
\end{tabular}

WEMWBS = Warwick-Edinburgh Mental Well-being Scale; $A D=$ antidepressant group with pre- and post-scores; $C C=$ 'cleaned' chaplaincy group with pre- and post-scores. $P$ value was calculated by an unpaired $t$ test comparing AD with CC.

\section{Summary}

There is marked similarity between all three groups for each of the baseline socio-demographic characteristics. The majority of participants were white females with a greater proportion of younger patients in the $\mathrm{AD}$ group and older patients in the $\mathrm{CC}$ group. Attrition rates are not significantly different between groups and do not impact on baseline WEMWBS. Initial WEMWBS differs between groups with (AD) being the lowest. However, each groups' initial WEMWBS correlates with the same CES-D category - 'at risk for major depression'.

\section{Pre- and post-intervention WEMWBS scores}

a. Change in WEMWBS score: Paired $t$ tests were used to test for difference in pre- and postintervention scores for each group. AD mean (SD) $8.81 \quad(9.08), \quad 95 \%$ CI $6.79-10.83$, $P<0.0001$. CC 7.53(8.92), 95\% CI 4.86-10.21, $P<0.0001$. First and final scores were used. Although not formally tested, there appeared to be a slight trend towards a linear increase in WEMWBS score when 6- and 12-week scores were compared in the CC group. There was no trend identifiable in 6- and 12-week scores in the AD group.

Primary Health Care Research \& Development 2017; 18: 354-365 b. Comparison of improvement in WEMWBS between groups: Table 4 displays this data and shows AD compared with CC. An unpaired $t$ test was used to test for difference. There is no significant difference in improvement between the groups as shown in Figure 2.

c. Comparison of responders between the groups: This was calculated by $\chi^{2}$ test. A score of 7 or more was used as the definition of clinical response. As seen in Table 5, there was no significant difference in response rate between the groups. It is noteworthy that both chaplaincy and antidepressants were effective in just over $50 \%$ of participants.

d. Comparison of initial WEMWBS with improvement in WEMWBS: This was calculated with Pearson's two-tailed test and showed a weak inverse correlation $r=-0.395, \quad 95 \%$ CI -0.57 to $-0.19, P 0.0003$ in $\mathrm{AD}$ and a moderately strong inverse correlation $r=-0.471,95 \%$ CI -0.67 to $-0.21,0.0011$ in CC.

e. Number of follow-up appointments (GP or PCC): The number of follow-up appointments (GP only in $\mathrm{AD}$ and chaplain only in $\mathrm{CC}$ ) was compared between groups $\mathrm{AD}$ and $\mathrm{CC}$. AD mean (SD) 1.77 (1.03), 95\% CI 1.54-2.00. CC mean (SD) 1.98 (1.69), 95\% CI 1.51-2.45. There was no significant difference between the groups with $P$ value of 0.46 . 


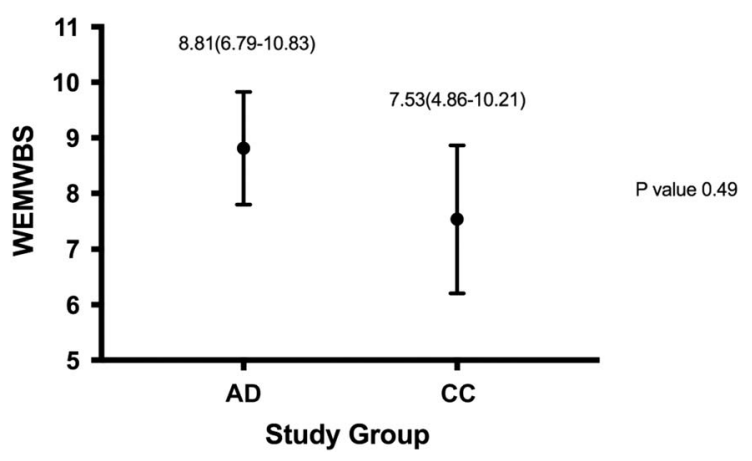

Figure 2 Comparison of change in Warwick-Edinburgh Mental Well-being Scale (WEMWBS) between groups expressed as mean with $95 \%$ confidence interval.

Table 5 Comparison of responders with non-responders between groups where 7 or greater is defined as response

\begin{tabular}{llll}
\hline & $\begin{array}{l}\text { AD } \\
(n=80)\end{array}$ & $\begin{array}{l}\text { CC } \\
(n=45)\end{array}$ & $\begin{array}{l}\text { Test of } \\
\text { difference }\end{array}$ \\
\hline $\begin{array}{l}\text { Number of patients } \\
\text { Responders }[n(\%)]\end{array}$ & $42(52.5)$ & $23(51)$ & $P$ \\
$\begin{array}{l}\text { value }=0.92 \\
\text { Non-responders }[n(\%)]\end{array}$ & $38(47.5)$ & $22(49)$ &
\end{tabular}

$A D=$ antidepressant group with pre- and post-scores; $\mathrm{CC}=$ 'cleaned' chaplaincy group with pre- and post-scores.

${ }^{a} P$ value was calculated by $\chi^{2}$ test.

f. Number of follow-up appointments (GP): The number of follow-up appointments (GP only in both $\mathrm{AD}$ and $\mathrm{CC}$ ) was compared between groups $\mathrm{AD}$ and $\mathrm{CC}$. AD mean (SD) 1.77 (1.03), 95\% CI 1.54-2.00. CC mean (SD) 0.91 (1.19), 95\% CI 0.56-1.24. An unpaired $t$ test showed a significantly lower mean follow-up rate in the PCC group with $P$ value $<0.0001$.

\section{Summary}

Both groups showed a significant increase in WEMWBS score post-intervention, with each being $>7$. The improvements were very similar with no significant difference evident between the groups. This trend seemed to be further clarified when analysed by comparison of responders to nonresponders.

The increase in well-being scores in PCC, therefore seems to be non-inferior to antidepressants. This increase in well-being scores in
PCC has occurred in a homogenously Caucasian population, and when used as the sole intervention without co-use of antidepressants. The CC group showed the highest inverse correlation between initial and final WEMWBS suggesting those with the lowest initial scores tend to derive the greatest benefit from intervention. The number of followup appointments with a GP was significantly less in the CC group.

\section{Discussion}

\section{Comparison with previous studies}

This study has similar findings to the previous research in PCC (Kevern and Hill, 2015). We found an evidence-based clinically significant improvement (Maheswaran et al., 2012) in well-being after PCC intervention. We, like the above authors, found a significant inverse correlation between initial WEMWBS and change in WEMWBS.

Each group in this study was predominately female. This is in keeping with other population studies of mental health which show females to have higher rates of depression, medication use and use of mental health services (Van der Heyden et al., 2009). The challenge then remains as to how to promote mental health services such as PCC to men. A larger study would allow subgroup analysis and provide insights into men's use of PCC.

This study differs from previous research in that the ethnicity of participants was homogenous, being nearly uniformly Caucasian. This is a helpful finding as it seems to validate the use of PCC in this particular cohort, which can be representative of certain demographics in the United Kingdom, as opposed to the more diverse initial study population mentioned above. This study is also different from previous research (Kevern, 2015), in that it shows a reduction in follow-up GP appointments in the PCC group relative to the AD group.

\section{Principal findings}

A major benefit of this study is the creation of the 'cleaned' chaplaincy group. To the author's knowledge this is the first study that has looked at PCC and controlled for concurrent use of antidepressants by creating the (CC) subgroup. This study shows an association between PCC and an improvement in well-being score. The improvement is defined in the literature as being significant (Maheswaran 
et al., 2012). Furthermore, the inverse correlation between initial WEMWBS score and change in WEMWBS score was highest in PCC. This novel data seems to add to the literature and shows PCC emerging on its own merits as a valid intervention for low well-being and depression. In light of this improvement in well-being, it would be reasonable for clinicians to have an increased confidence in the use of PCC.

As already noted such talking therapies are politically favoured currently (Gray, 2015). It is also known that less than half of patients referred enter such services (Wise, 2014) with some of this dropout rate felt to be due to delay in access. The model of PCC used in the author's practice and the other models noted above, overcome this through an onsite chaplain integrated fully into the primary care team. This allows a flexible responsive service which further promotes PCC as a viable alternative option.

A recent metanalysis has shown the talkingbased therapy, cognitive behavioural therapy to be as effective as second generation antidepressants (Amick et al., 2015). Reflecting on this, the other main objective of this study was to treat PCC as a type of talking therapy and assess its effectiveness relative to the use of antidepressants. PCC has been shown to be associated with an improvement in WEMWBS in line with that of antidepressants. There was no significant difference in improvement between the groups. This suggests that PCC (and PCC alone) is associated with similar improvements in well-being to that of antidepressants and certainly is no worse. This seems to justify its use as a 'talking therapy' alternative to medication.

Although it could be argued that antidepressants and PCC are therefore of similar value it seems reasonable to assume they have some specific contexts that enhance their respective usefulness. The (AD) group had a lower initial well-being. It may well be that such patients would not engage as well with PCC until their well-being score improves to the baseline we see in the PCC group. Perhaps use of antidepressants and PCC should be matched to presenting well-being score to maximise potential improvement in well-being. It is noteworthy, that the PCC group showed the strongest inverse correlation between low baseline well-being and improvement in well-being. This does suggest those attending PCC with low scores will tend to have the best outcomes. PCC could also be utilised when there is a need to reduce the burden of treatment and polypharmacy. This is likely to be particularly beneficial in the LTC's mentioned above. Finally, antidepressants are reported to have both physical (Bet et al., 2013) and emotional (Price et al., 2012) side effects. PCC can be offered as a useful treatment option in patients keen to avoid these potential issues or in those who have specific contraindications.

There does seem to be a lower number of followup GP appointments in the PCC group relative to the AD group. It is possible this was achieved by their attendance at PCC. However, this simply reflects their GP appointments relative to the AD group and not their personal reduction of appointments before and after PCC intervention.

\section{Strengths of study}

This study has met it is initial objectives and has demonstrated an association between improvement in well-being and PCC, relative to antidepressants in a homogenous population. It seems in line with and additive to existing research. There was a good follow-up rate with no difference in initial well-being of those LTFU.

\section{Limitations of study}

As this study is not a prospective randomised controlled trial it is open to sources of bias and confounding. In an attempt to mitigate against this, socio-demographic features were compared between groups and encouragingly no significant differences were found. There was, however, a difference in baseline WEMWBS between the groups. This may imply a difference in nature as well as severity of loss of well-being that may alter potential for change in WEMWBS. Selection bias may have been a feature. Patients who choose to attend chaplaincy may be more likely to respond to such input than those who request antidepressants. The converse may also be true. Confounding may also play a role in that the distribution of reactive triggers and negative life events during the follow-up period may not have been equally distributed between groups, thus affecting outcomes. A further factor may have been the difference in practioner input with the potential for a greater improvement arising simply from more practioner input. There were, for example, a greater number of follow-up GP appointments in the antidepressant group. It is acknowledged that PCC appointments are much longer than GP 
appointments pointing to the likely qualitative difference accounting for improvement in the PCC group. Finally, some patients in the antidepressant group may also have accessed counselling.

\section{Conclusion}

This study has shown that PCC (used as sole therapy) is associated with an improvement in well-being and has justified its use relative to antidepressants. This has been found to apply to those with loss of wellbeing and those at risk of major depression. Given the growing body of evidence it now seems reasonable to proceed to a prospective trial. This should ideally be done in the form of a multicentre randomised controlled trial comparing PCC with antidepressants. This would reduce bias and confounding, would allow detailed subgroup analysis and matching of initial WEMWBS between groups.

It is recognised that PCC is still in it is embryonic phase. It is hoped that the above findings combined with those cited will increase clinician and patient confidence in the service. There remain many issues such as: which model is most effective, how to establish PCC in other practices and resources of time and people. Each of these are worthy of further research.

As we continue to navigate the road map of patient care it looks like PCC may well be a useful intervention for patients, particularly those with modern maladies and LTC.

\section{Acknowledgements}

With particular thanks to Sarah Giffen Principal Chaplain Regent Gardens Medical Practice. The author thanks Katie Gilmore for help with data checking.

\section{Financial Support}

This study received no specific grant from any funding agency, commercial or not-for-profit sectors.

\section{Ethical Standards}

Ethical permission was discussed with the West of Scotland NHS Ethics Service and deemed not to be necessary as the study was a pure service evaluation and analysis of routinely collected data.

\section{Conflicts of Interest}

The author is the clinical lead for PCC in the practice.

\section{References}

Amick, H.R., Gartlehner, G., Gaynes, B.N., Forneris, C., Asher, G.N., Morgan, L.C., Coker-Schwimmer, E., Boland, E., Lux, L.J., Gaylord, S., Bann, C., Pierl, C.B. and Lohr, K.N. 2015: Comparative benefits and harms of second generation antidepressants and cognitive behavioral therapies in initial treatment of major depressive disorder: systematic review and meta-analysis. BMJ 351, h6019.

Barnett, K., Mercer, S.W., Norbury, M., Watt, G., Wyke, S. and Guthrie, B. 2012: Epidemiology of multimorbidity and implications for health care, research, and medical education: a cross-sectional study. Lancet 380, 37-43.

Bartram, D.J., Sinclair, J.M. and Baldwin, D.S. 2013: Further validation of the Warwick-Edinburgh Mental Well-being Scale (WEMWBS) in the UK veterinary profession: Rasch analysis. Quality of Life Research 22, 379-91.

Bet, P.M., Hugtenburg, J.G., Penninx, B.W. and Hoogendijk, W.J. 2013: Side effects of antidepressants during long-term use in a naturalistic setting. European Neuropsychopharmacology 23, 1443-451.

Braunholtz, S., Davidson, S., Myant, K. and O'Conner, R. 2007: Well? What do you think? (2006). The third national survey of Scottish attitudes to mental health, mental wellbeing and mental health problems, Scottish Executive, Edinburgh.

Brown, S.J.K. 2008: Warwick-Edinburgh Mental Wellbeing Scale (WEMWBS). Edited by Parkinson, J., User guide version 1 . NHS Health Scotland.

Bryson, P., Dawlatly, S., Hughes, A., Bryson, E. and Petra, H. 2012: Honouring personhood in patients: the added value of chaplaincy in general practice. England: Whole Person Health Trust.

Bunniss, S.M.H. 2013: Community chaplaincy listening: practical theology in action. Scottish Journal of Healthcare Chaplaincy 16 (Special), 42-51.

Christensen, K., Doblhammer, G., Rau, R. and Vaupel, J.W. 2009: Ageing populations: the challenges ahead. Lancet 374 , 1196-208.

Cimpean, D. and Drake, R.E. 2011: Treating co-morbid chronic medical conditions and anxiety/depression. Epidemiology and Psychiatric Sciences 20, 141-50.

Delgado-Guay, M.O. 2014: Spirituality and religiosity in supportive and palliative care. Current Opinion in Supportive and Palliative Care 8, 308-13.

DOH 2011: Talking therapies: A four year plan of action. A supporting document to No health without Mental Health: A cross-government mental health outcomes strategy for people of all ages. p. 2-24. Retrieved 8 August 2016 from https://www. gov.uk/government/publications/talking-therapies-a-4-yearplan-of-action

Donatella, B. 2012. The performance of the Warwick Edinburgh Mental Wellbeing Scale as a screening tool for depression in the $U K$ and in Italy. Italy: University of Bologna.

Dowrick, C. and Frances, A. 2013: Medicalising unhappiness: new classification of depression risks more patients being 
put on drug treatment from which they will not benefit. $B M J$ $347, \mathrm{f} 7140$.

Ehman, J.W., Ott, B.B., Short, T.H., Ciampa, R.C. and HansenFlaschen, J. 1999: Do patients want physicians to inquire about their spiritual or religious beliefs if they become gravely ill? Archives of Internal Medicine 159, 1803-806.

Gray, P. 2015: Politicians vie to support access to talking therapies on NHS. BMJ 350, h896.

Hanlon, P., Carlisle, S., Hannah, M., Reilly, D. and Lyon, A. 2011: Making the case for a 'fifth wave' in public health. Public Health 125, 30-36.

Hofmann, B. 2016: Obesity as a socially defined disease: philosophical considerations and implications for policy and care. Health Care Analysis 24, 86-100.

Kevern, P. and Hill, L. 2015: 'Chaplains for well-being' in primary care: analysis of the results of a retrospective study. Primary Health Care Research \& Development 16, 87-99.

Kevern, P. and Ladbury, I. 2015: Resource implications of a measured change in patient wellbeing: a retrospective cohort analysis study. The Journal of New Writing in Health and Social Care 2.

King, M.B. and Koenig, H.G. 2009: Conceptualising spirituality for medical research and health service provision. $B M C$ Health Services Research 9, 116.

Maheswaran, H., Weich, S., Powell, J. and Stewart-Brown, S. 2012: Evaluating the responsiveness of the Warwick Edinburgh Mental Well-Being Scale (WEMWBS): group and individual level analysis. Health and Quality of Life Outcomes 10, 156.

Mair, F.S. and May, C.R. 2014: Thinking about the burden of treatment. BMJ 349, g6680.

Manning, L.K. 2014: Enduring as lived experience: exploring the essence of spiritual resilience for women in late life. Journal of Religion and Health 53, 352-62.

Maslow, A.H. 1943: A theory of human motivation. Psychological Review 50, 370-96.

Maslow, A.H. 1970 [1964]. Religions, experience and peak values. New York: Penguin.

Mathers, N. 2014: James Mackenzie Lecture 2013: the Tao of family medicine. British Journal of General Practice 64, e675-677.

Mcsherry, W., Boughey, A. and Kevern, P. 2016: 'Chaplains for wellbeing' in primary care: a qualitative investigation of their perceived impact for patients' health and wellbeing. Journal of Health Care Chaplaincy 22, 151-70.

Moscrop, A. 2011: Medicalisation, morality, and addiction: why we should be wary of problem gamblers in primary care. British Journal of General Practice 61, e836-838.

Mowat, H.B. and S. Kelly, E. 2012: Community chaplaincy listening: working with general practioner to support patient wellbeing. Scottish Journal of Healthcare Chaplaincy 15 (1), 27-35.

Moynihan, R. 2011: Medicalization. A new deal on disease definition. BMJ 342, d2548.

Oliver, D. 2012: 21st century health services for an ageing population: 10 challenges for general practice. British Journal of General Practice 62, 396-97.

Primary Health Care Research \& Development 2017; 18: 354-365
Pargament, K. 1999: The psychology of religion and spirituality? Yes and no. The International Journal for the Psychology of Religion 9, 3-16.

Price, J., Cole, V., Doll, H. and Goodwin, G.M. 2012: The Oxford Questionnaire on the Emotional Side-effects of Antidepressants (OQuESA): development, validity, reliability and sensitivity to change. Journal of Affective Disorders 140, 66-74.

Puchalski, C., Ferrell, B., Virani, R., Otis-Green, S., Baird, P., Bull, J., Chochinov, H., Handzo, G., Nelson-Becker, H., Prince-Paul, M., Pugliese, K. and Sulmasy, D. 2009: Improving the quality of spiritual care as a dimension of palliative care: the report of the consensus conference. Journal of Palliative Medicine 12, 885-904.

Radloff, L.S. 1977: The CES-D scale. Applied Psychological Measurement I (3), 385-401.

Scottish Executive Health Department HDL 2002: 76 spiritual care in NHSScotland, SEHD HDL. Guidelines on Chaplaincy and Spiritual Care in the NHS in Scotland. Retrieved 18 August 2016 from www.sehd.scot.nhs.uk/mels/hd12002_76.pdf

Scottish Government Department of Health and Wellbeing 2008: Spiritual care and chaplaincy in NHSScotland CEL 49, SGDH. Guidelines on Chaplaincy and Spiritual Care in the NHS in Scotland, Annex A Paragraph 5-17. Retrieved 18 August 2016 from www.sehd.scot.nhs.uk/mels/CEL2008_49.pdf

Tanyi, R.A. 2002: Towards clarification of the meaning of spirituality. Journal of Advanced Nursing 39, 500-9.

Tennant, R., Hiller, L., Fishwick, R., Platt, S., Joseph, S., Weich, S., Parkinson, J., Secker, J. and Stewart-Brown, S. 2007: The Warwick-Edinburgh Mental Well-being Scale (WEMWBS): development and UK validation. Health and Quality of Life Outcomes 5, 63.

Vallurupalli, M., Lauderdale, K., Balboni, M.J., Phelps, A.C., Block, S.D., Ng, A.K., Kachnic, L.A., Vanderweele, T.J. and Balboni, T.A. 2012: The role of spirituality and religious coping in the quality of life of patients with advanced cancer receiving palliative radiation therapy. Journal of Supportive Oncology 10, 81-87.

Van Der Heyden, J.H., Gisle, L., Hesse, E., Demarest, S., Drieskens, S. and Tafforeau, J. 2009: Gender differences in the use of anxiolytics and antidepressants: a population based study. Pharmacoepidemiology and Drug Safety 18, 1101-110.

Vazquez, F.L., Blanco, V. and Lopez, M. 2007: An adaptation of the Center for Epidemiologic Studies Depression Scale for use in non-psychiatric Spanish populations. Psychiatry Research 149, 247-52.

Vermandere, M., De Lepeleire, J., Smeets, L., Hannes, K., Van Mechelen, W., Warmenhoven, F., Van Rijswijk, E. and Aertgeerts, B. 2011: Spirituality in general practice: a qualitative evidence synthesis. British Journal of General Practice 61, e749-760.

Williams, J.A., Meltzer, D., Arora, V., Chung, G. and Curlin, F.A. 2011: Attention to inpatients' religious and spiritual concerns: predictors and association with patient satisfaction. Journal of General Internal Medicine 26, 1265-271.

Wise, J. 2014: Only half of patients referred for talking therapies enter treatment. BMJ 348, g295. 


\section{Appendix 1}

\section{Below are some statements about feelings and thoughts.}

Please tick $(\underline{\sqrt{ })}$ the box that best describes your experience of each over the last $\mathbf{2}$ weeks

\begin{tabular}{|c|c|c|c|c|c|}
\hline Statements & None of the time & Rarely & Some of the time & Often & All of the time \\
\hline I've been feeling optimistic about the future & 1 & 2 & 3 & 4 & 5 \\
\hline I've been feeling useful & 1 & 2 & 3 & 4 & 5 \\
\hline I've been feeling relaxed & 1 & 2 & 3 & 4 & 5 \\
\hline I've been feeling interested in other people & 1 & 2 & 3 & 4 & 5 \\
\hline I've had energy to spare & 1 & 2 & 3 & 4 & 5 \\
\hline I've been dealing with problems well & 1 & 2 & 3 & 4 & 5 \\
\hline I've been thinking clearly & 1 & 2 & 3 & 4 & 5 \\
\hline I've been feeling good about myself & 1 & 2 & 3 & 4 & 5 \\
\hline I've been feeling close to other people & 1 & 2 & 3 & 4 & 5 \\
\hline I've been feeling confident & 1 & 2 & 3 & 4 & 5 \\
\hline I've been able to make up my own mind about things & 1 & 2 & 3 & 4 & 5 \\
\hline I've been feeling loved & 1 & 2 & 3 & 4 & 5 \\
\hline I've been interested in new things & 1 & 2 & 3 & 4 & 5 \\
\hline I've been feeling cheerful & 1 & 2 & 3 & 4 & 5 \\
\hline
\end{tabular}

CWEMWBS

Warwick-Edinburgh Mental Well-being Scale (WEMWBS) ${ }^{\odot}$ NHS Health Scotland, University of Warwick and University of Edinburgh, 2006, all rights reserved. 